\title{
Synthesis and Ring-Opening Metathesis Polymerization of Second-Generation Dendronized Poly(ether) Monomers Initiated by Ruthenium Carbenes
}

\author{
Pablo E. Guzmán ${ }^{1 *}$, Victoria A. Piunova ${ }^{2}$, Garret M. Miyake ${ }^{3}$ and Robert H. Grubbs ${ }^{1}$ \\ ${ }^{1}$ Arnold and Mabel Beckman Laboratories for Chemical Synthesis, Division of Chemistry and Chemical Engineering, \\ California Institute of Technology, Pasadena, California 91125 - United States \\ 2 IBM Almaden Research Center, 650 Harry Road, San Jose California 95134 - United States \\ ${ }^{3}$ Department of Chemistry and Biochemistry, Materials Science and Engineering Program, University of Colorado, Boulder, \\ Colorado 80309 - United States \\ e-mail: peguzman@caltech.edu -vapiunov@us.ibm.com-garret.miyake@colorado.edu -rhg@caltech.edu \\ * Corresponding author
}

\begin{abstract}
The Ring-Opening Metathesis Polymerization (ROMP) of second-generation dendronized monomers is described. Using the highly active and fast-initiating third-generation ruthenium complex [( $\left.\left.\mathrm{H}_{2} \mathrm{IMes}\right)(\mathrm{pyr})_{2} \mathrm{Cl}_{2} \mathrm{RuCHPh}\right]$, moderate to high molecular weight polymers $(430-2230 \mathrm{kDa})$ are efficiently synthesized with low dispersities $(\boxplus=1.01-1.17)$. This study highlights the power of the metathesis approach toward polymer synthesis in a context where monomer structure can significantly impede polymerization.
\end{abstract}

Résumé - La synthèse et la polymérisation par ouverture de cycle par métathèse des monomères poly(éther) de deuxième génération initié par le catalyseur de ruthénium de troisième génération - La polymérisation par ouverture de cycle par métathèse (ROMP, Ring-Opening Metathesis Polymerization) de monomers dendronisés de deuxième génération est décrite. En utilisant le complexe de ruthénium ayant une activité élevée et une initiation rapide de troisième génération $\left[\left(\mathrm{H}_{2} \mathrm{IMes}\right)(\mathrm{pyr})_{2} \mathrm{Cl}_{2} \mathrm{RuCHPh}\right]$, des polymères de masses moléculaires modérées à élevées $(430$ à $2230 \mathrm{kDa})$ sont synthétisés de manière efficace avec de basses polydispersités $(\bigoplus=1,01$ à 1,17). Cette étude met en évidence la puissance de l'approche de métathèse vers la synthèse de polymères dans un contexte où la structure de monomère peut empêcher de manière significative la polymérisation.

\section{INTRODUCTION}

Since its discovery nearly six decades ago, olefin metathesis has evolved into a powerful method for the formation of $\mathrm{C}-\mathrm{C}$ bonds, enabling the synthesis of simple to complex organic molecules [1]. Y. Chauvin proposed the commonly accepted mechanism for metathesis (Scheme 1), which illustrates the crucial involvement of a metal carbene and metallacyclobutane intermediate [2].
Ring-Opening Metathesis Polymerization (ROMP), an application of the metathesis reaction to polymer synthesis, has made a tremendous impact on synthetic polymer chemistry [3-8]. Well-defined and complex polymer architectures are readily synthesized through judicious identification of monomer and initiator. Norbornene and its functionalized derivatives have proven to be archetypical polymer precursors because of facile synthesis, affordability, and reactivity [9]. Moreover, the combination of inherent living characteristics 

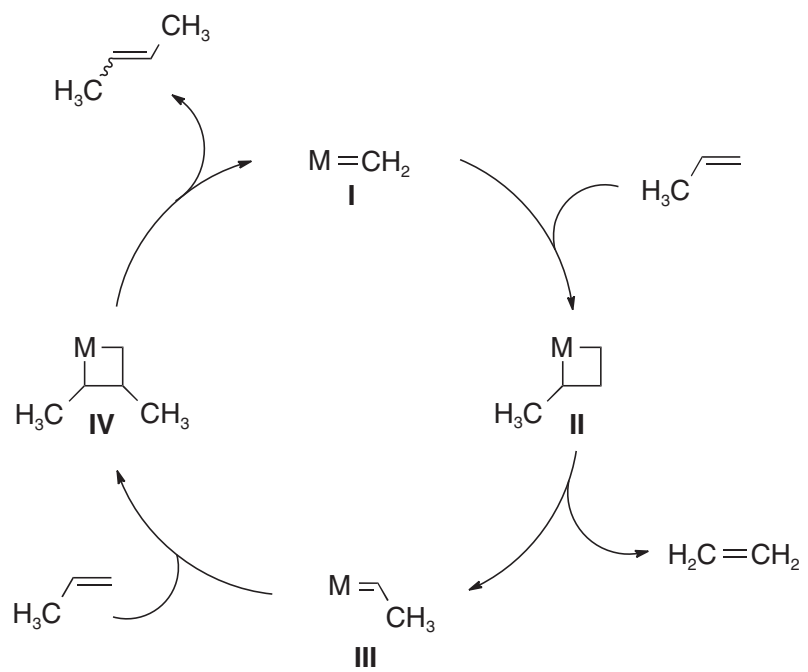

Scheme 1
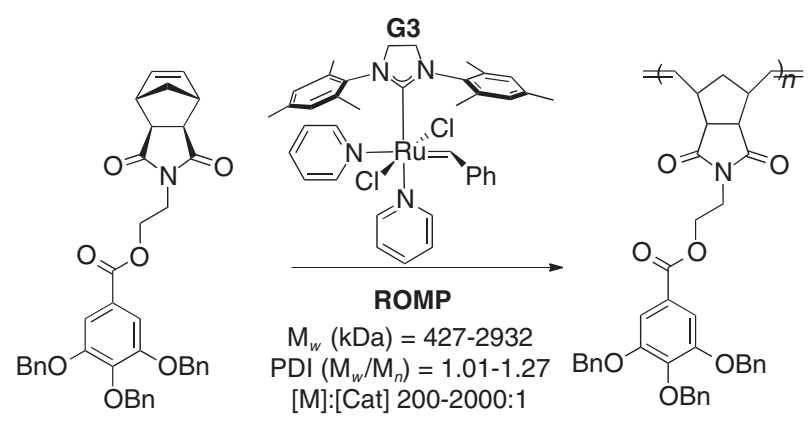

Scheme 2

Polymerization of first-generation wedge-type monomers with G3.

and practicality associated with ROMP has made it a powerful tool among chemists and materials scientists [10].

Recently, our interest in ROMP has been directed towards the synthesis of molecular brush and dendronized block copolymers and their self-assembly to visible light reflecting one-Dimensional Photonic Crystals (1D PC) [11-19]. Photonic crystals are periodic nanostructured materials that possess a photonic band gap that inhibits select frequencies of light from propagating through the bulk material [15-19]. The access of periodicities large enough to interact with visible light is a challenge with block copolymers because of their inherent macromolecular chain-entanglement [20]. However, though the design and synthesis of polymer architectures that reduce chain-entanglement, we have demonstrated that such block copolymers can rapidly

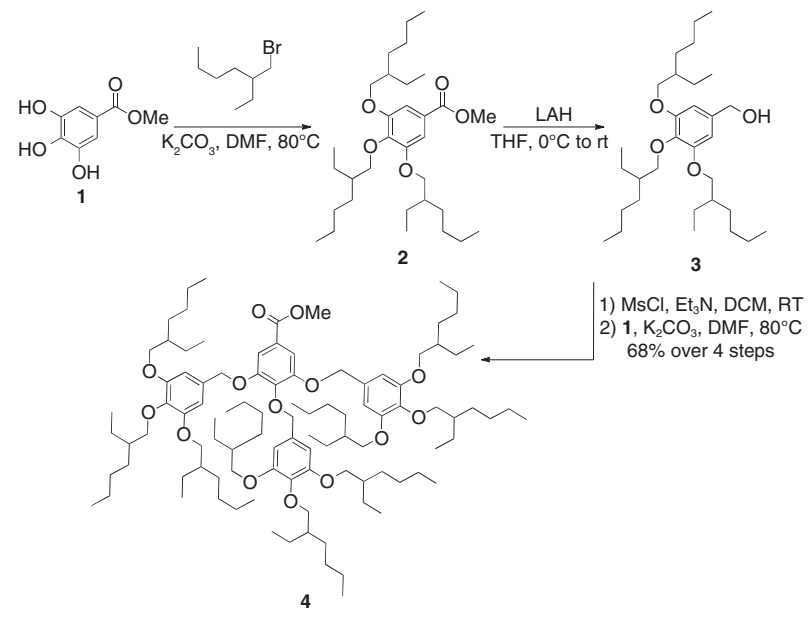

Scheme 3

Synthesis of dendronized ester 4 .

self-assemble to photonic crystals that reflect wavelengths of light across the visible spectrum and into the IR.

For instance, in the presence of the third-generation bis-pyridine initiator (G3), an efficient polymerization of discrete first-generation wedge-type monomers containing a functionalized exo-norbornene backbone tethered to a 1, 3, 4, 5-tetrasubstituted aromatic pendant/anchor group was achieved (Scheme 2) [21]. Ratios ([monomer]:[initiator]) ranging from 200-2000:1, provided a broad range of Molecular Weights (MW) (weight average MW $\left(M_{\mathrm{w}}\right)=427$ to $2932 \mathrm{kDa}$ ) along with low dispersities (Đs) $(\mathrm{PDI}=1.01-1.27)$. The sequential copolymerization with an appropriate first-generation wedge-type monomer provided facile entry to block copolymers capable of selfassembling to 1D PC. However, at high MW (e.g. $M_{\mathrm{w}}=$ 1390-1940 kDa), self-assembly proved challenging, presumably due to chain entanglement. Thus, we hypothesized that an additional generation to the existing wedge-type system would increase polymer rigidity and decrease the propensity for chain entanglement.

Notably, previous studies have shown that if the linker length between the polymerizing exo-norbornene group and the pendant/anchor group is too short $(<10$ methylene units), similar second-generation dendronized monomers could not be efficiently polymerized to high MW polymers using similar carbene initiators [22]. In this manuscript, we challenge the ROMP method and showcase the ability of the highly active $\mathbf{G 3}$ initiator to ring-open and polymerize sterically hindered dendronized MacroMonomers (MM) with short linker lengths to yield high MW homopolymers under ambient conditions. We envisioned that the incorporation of a highly reactive exo-norbornene carbodiimides polymerizable functionality (due to the excess ring strain) would 


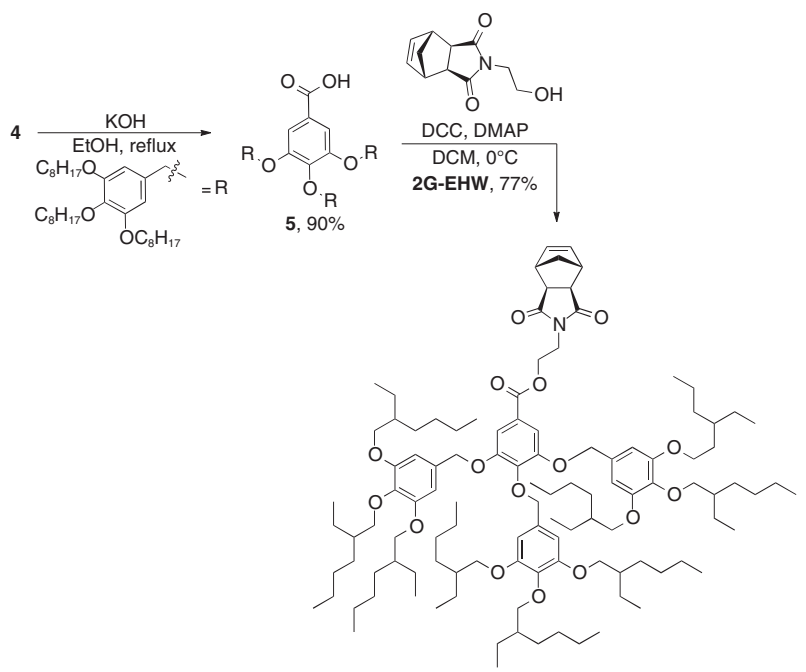

Scheme 4

Synthesis of dendronized monomer 2G-EHW.

allow successful polymerization of second-generation wedge monomers with short linkers.

\section{RESULTS AND DISCUSSION}

Our approach to second-generation dendronized macromonomers was realized through the execution of standard organic transformations. Ester 4 was synthesized in a 4-step sequence starting from methyl gallate 1 (Scheme 3). A three-fold O-alkylation with 2-ethylhexyl bromide provided compound 2, which was reduced to its corresponding benzyl alcohol (3) with Lithium Aluminum Hydride (LAH). The treatment of $\mathbf{3}$ with mesyl chloride followed by nucleophilic displacement of the corresponding mesylate with 1 yielded the desired ester in $68 \%$ yield over four steps.

The exposure of $\mathbf{4}$ to alkaline conditions in boiling alcoholic solvent led to the formation of the corresponding carboxylic acid 5 which was isolated in $90 \%$ yield (Scheme 4). N, N'-dicyclohexylcarbodiimide (DCC) coupling with $N$-(hydroxyethyl)-cis-5-norbornene-exo-2, 3, dicarboximide furnished the desired second-generation ethylhexyl wedge dendronized macromonomer (2G-EHW) in $77 \%$ yield.

The ROMP of 2G-EHW led to the controlled synthesis of second-generation wedge-type polymers capable of being carried out over a broad range of [2G-EHW]:[G3] ratios. High conversions and remarkably low $Đ s$ (entries 1-3) were achieved despite a short linker length (2 methylene units) and an extensive alkylether periphery (Tab. 1, Fig. 1).
TABLE 1

Results of the ROMP of 2G-EHW mediated by $\mathbf{G 3}^{\text {a }}$

\begin{tabular}{c|c|c|c|c}
\hline Entry & {$[\mathrm{MM}] /[\mathrm{G} 3]$} & Conv $^{\mathrm{b}}$ & $M_{\mathrm{w}}(\mathrm{kDa})^{\mathrm{c}}$ & $Ð\left(M_{\mathrm{w}} / M_{\mathrm{n}}\right)^{\mathrm{c}}$ \\
\hline 1 & 200 & 100 & 4.29 & 1.01 \\
\hline 2 & 400 & 99 & 1055 & 1.03 \\
\hline 3 & 600 & 90 & 2086 & 1.17 \\
\hline 4 & 800 & 65 & 2230 & 1.42 \\
\hline 5 & 1000 & 0 & - & - \\
\hline
\end{tabular}

${ }^{a}$ Polymerizations performed in $1 \mathrm{~mL}$ of THF over 2 hours at ambient temperature. $[\mathbf{2 G - E H W}]=90 \mathrm{mM}$.

${ }^{\mathrm{b}}$ Determined by ${ }^{1} \mathrm{H}$ NMR.

${ }^{\mathrm{c}}$ Determined by light scattering.

However, the reaction efficiency decreases or fails to polymerize at ratios greater than 800:1 [2G-EHW]:[G3] (Fig. 2) [23]. Nonetheless, the controlled synthesis of polymers with MW nearing $2100 \mathrm{kDa}$ were efficiently achieved.

Detailed kinetic studies established a complete kinetic profile for monomer 2G-EHW. A linear increase in MW with an increase in monomer conversion (Fig. 1a) and nearly constant $Ð$ was observed during the course of polymerization; consistent with living polymerization characteristics (Fig. 3). Accordingly, for all the [2G-EHW]:[G3] ratios investigated a first-order dependence on [2G-EHW] was observed (Fig. 1b).

\section{EXPERIMENTAL}

\subsection{General Considerations}

$\left(\mathrm{H}_{2} \mathrm{IMes}\right)\left(\mathrm{PPh}_{3}\right)_{2}(\mathrm{Cl})_{2} \mathrm{RuCHPh}$ was received as a research gift from Materia Inc. and converted to $\mathbf{G} 3$ via literature procedures [24]. All other chemicals were purchased from Sigma Aldrich. Solvents were purified by passage through solvent purification columns and further degassed with argon [25]. N-(hydroxyethyl)-cis-5-norbornene-exo-2,3 dicarboximide was prepared according to literature procedure [26]. All reactions were carried out in flame-dried Schlenktype glassware on a dual-manifold Schlenk line or in a nitrogen-filled glovebox. NMR spectra were recorded on a Varian Inova $500 \mathrm{MHz}$ spectrometer. Chemical shifts were referenced to internal solvent resonances and are reported as parts per million relative to tetramethylsilane. High resolution mass spectra were provided by the California Institute of Technology Mass Spectrometry Facility. Compound 2G-EHW was analyzed by MALDI-TOF in reflector mode using a Voyager DE PRO time-of-flight mass spectrometer (Applied Biosystems). The MALDI matrix used was 

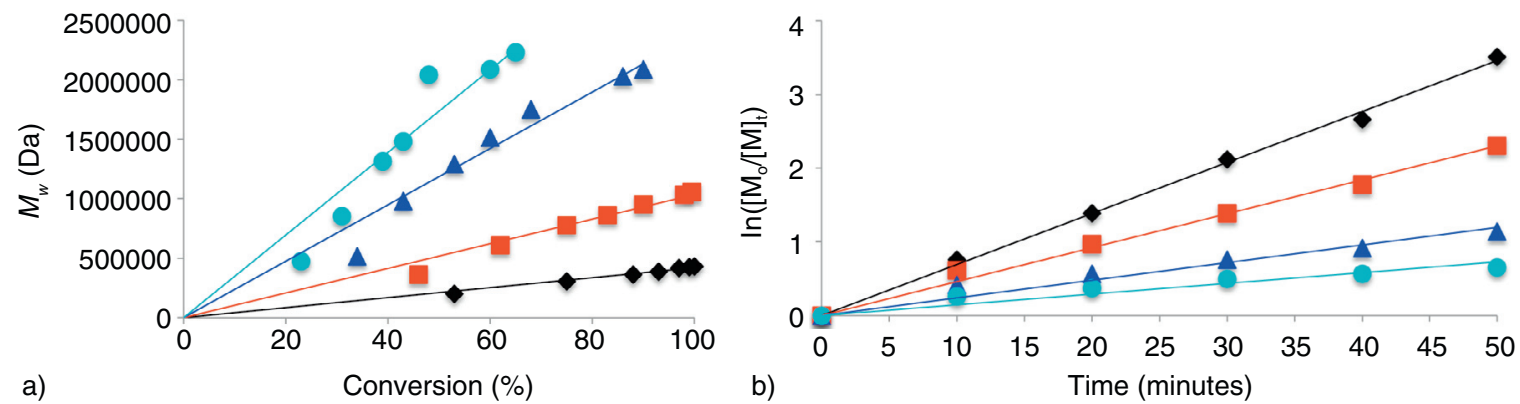

Figure 1

a) Plot of $M_{\mathrm{w}}$ as a function of 2G-EHW conversion ([2G-EHW]:[G3] = $200(\bullet), 400(\square), 600(\boldsymbol{\Delta}), 1000(\odot)$. b) Semilogarithmic plots of $\ln \left(\left[\mathbf{2 G}-\mathbf{E H W}_{o}\right] /\left[\mathbf{2 G}_{\mathbf{G}} \mathbf{E H W} \mathbf{W}_{t}\right]\right)$ as a function of time for the ROMP of 2G-EHW by G3. Conditions: [2G-EHW] $=90 \mathrm{mM}$; $[\mathbf{G 3}]=450 \mu \mathrm{M}(\bullet)$, $220 \mu \mathrm{M}(\square), 150 \mu \mathrm{M}(\boldsymbol{\Delta}), 110 \mu \mathrm{M}(\odot)$. Polymerizations were performed in anhydrous/degassed THF at ambient temperature.

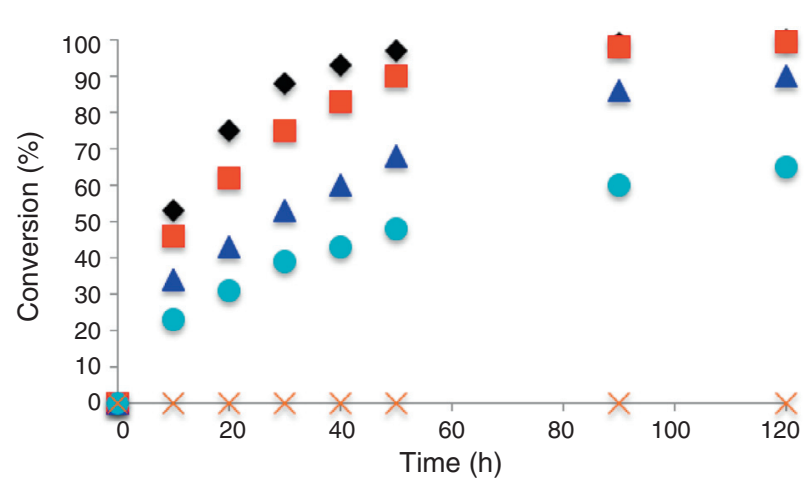

Figure 2

Kinetic data comparing the polymerization of 2G-EHW.

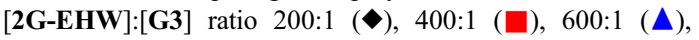
800:1 (○), 1000:1 (×).

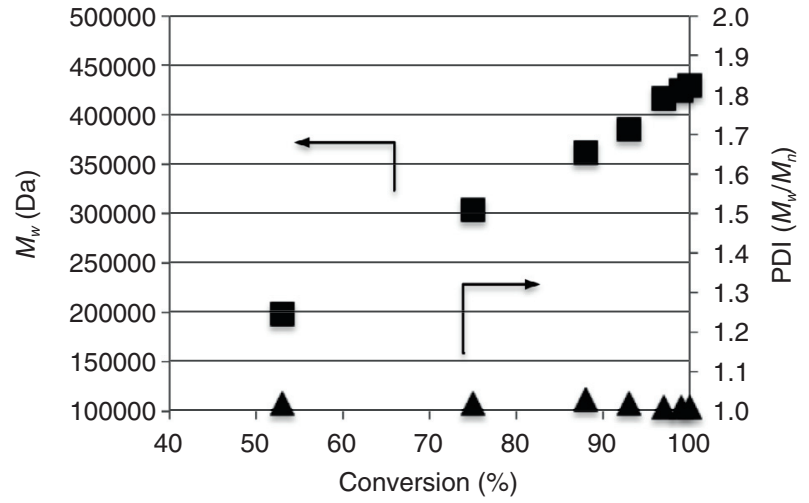

Figure 3

Plot of $M_{\mathrm{w}}$ (left) and $\oslash$ (right) as a function of 2G-EHW conversion ([2G-EHW]:[G3] = 200:1). dithranol prepared at $10 \mathrm{mg} / \mathrm{mL}$ in THF. The instrument was externally calibrated with the manufacturer Sequazyme $^{\mathrm{TM}}$ Kit. Polymer MW were determined utilizing THF as the eluent by MultiAngle Light-Scattering (MALS) Gel Permeation Chromatography (GPC) using a miniDAWN TREOS light-scattering detector, a Viscostar viscometer, and an OptilabRex refractive index detector, all from Wyatt Technology. An Agilent 1200 UV-Vis detector was also present in the detector stack. Absolute MW were determined using $d n / d c$ values calculated by assuming $100 \%$ mass recovery of the polymer sample injected into the GPC.

\subsection{Procedures}

To a flame dried $500 \mathrm{~mL}$ round-bottom flask equipped with a magnetic stir bar was added $\mathrm{K}_{2} \mathrm{CO}_{3}(55.0 \mathrm{~g}, 398 \mathrm{mmol}$, 8.00 eq), anhydrous DMF $(260 \mathrm{~mL})$, methyl gallate
(9.15 g, $49.7 \mathrm{mmol}, 1.00 \mathrm{eq})$ and 2-ethylhexyl bromide (53.0 mL, $298 \mathrm{mmol}, 6.00 \mathrm{eq})$. The reaction was fitted with a water-cooled condenser, placed under an inert atmosphere of argon and heated to $80^{\circ} \mathrm{C}$ for $14 \mathrm{~h}$. The reaction was stopped by the addition of $\mathrm{H}_{2} \mathrm{O}(500 \mathrm{~mL})$. The mixture was transferred to a separation funnel and the aqueous layer was washed with $\mathrm{Et}_{2} \mathrm{O}(3 \times 300 \mathrm{~mL})$. The organic layers were combined, washed with brine, dried over $\mathrm{MgSO}_{4}$, vacuum filtered and concentrated under reduced pressure. The material was used crude and subjected to reduction conditions.

To a $500 \mathrm{~mL}$ round-bottom flask containing crude ester 2 (49.7 mmol, $1.00 \mathrm{eq}$ ) was added anhydrous THF (155 mL). The solution was cooled to $0^{\circ} \mathrm{C}$. Once cool, $\mathrm{LAH}(3.77 \mathrm{~g}$, $99.4 \mathrm{mmol}, 2.00 \mathrm{eq})$ was carefully added. The reaction placed under an inert atmosphere of argon and allowed to stir and gradually warm to room temperature overnight. The reaction was cooled to $0^{\circ} \mathrm{C}$. Once cool, the reaction was 


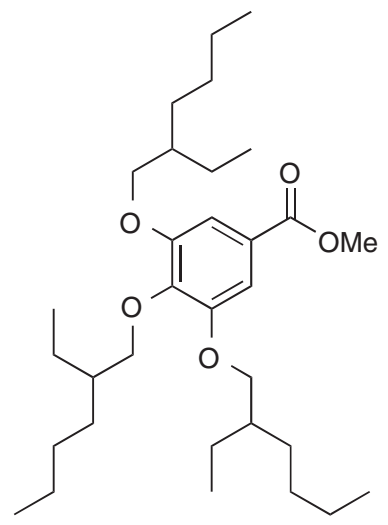

Figure 4

Methyl 3,4,5-tris((2-ethylhexyl)oxy)benzoate (2).

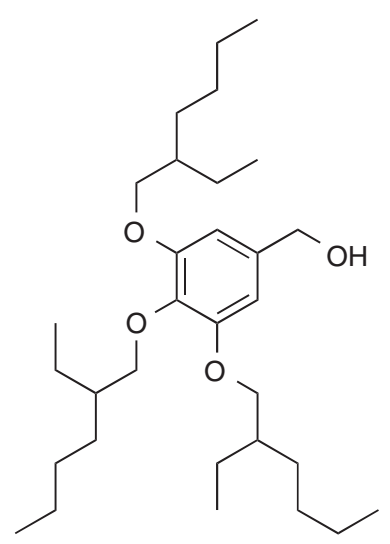

Figure 5

(3,4,5-tris((2-ethylhexyl)oxy)phenyl)methanol (3).

stopped by the addition of $\mathrm{H}_{2} \mathrm{O}(20 \mathrm{~mL})$ and diluted with $\mathrm{Et}_{2} \mathrm{O}$. A saturated aqueous solution of Rochelle's salt was added and the mixture was aggressively stirred for one hour. The two layers were separated and the aqueous layer was washed with $\mathrm{Et}_{2} \mathrm{O}(3 \times 300 \mathrm{~mL})$. The organic layers were combined, washed with brine, dried over $\mathrm{MgSO}_{4}$, vacuum filtered and concentrated under reduced pressure. The material was used crude for the next step.

To a $500 \mathrm{~mL}$ round-bottom flask containing crude alcohol 3 (49.7 mmol, 1.00 eq) was added anhydrous DCM $(165 \mathrm{~mL})$. The solution was cooled to $0^{\circ} \mathrm{C}$. Once cool, distilled $\mathrm{Et}_{3} \mathrm{~N}$ (10.3 mL, $\left.74.6 \mathrm{mmol}, 1.50 \mathrm{eq}\right)$ was added. $\mathrm{MsCl}$ (4.61 g, $59.6 \mathrm{mmol}, 1.20 \mathrm{eq}$ ) was carefully added dropwise over two minutes. The reaction was placed under an inert atmosphere of argon and allowed to stir and gradually warm to room temperature overnight. The reaction was stopped by

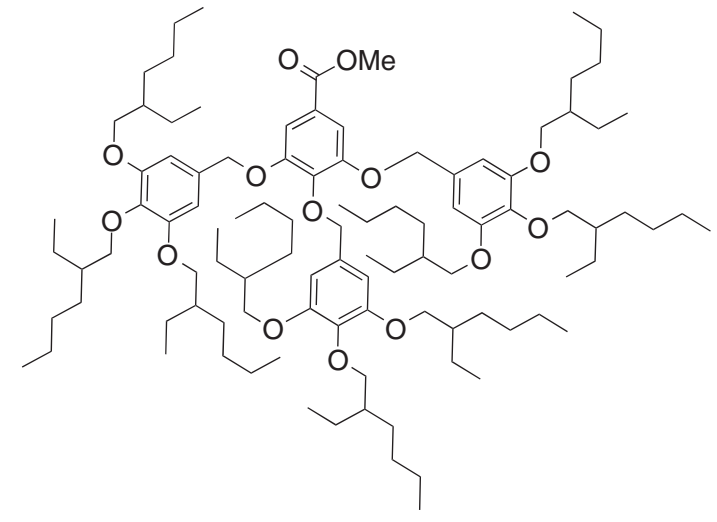

Figure 6

Methyl 3,4,5-tris((3,4,5-tris((2-ethylhexyl)oxy)benzyl)oxy) benzoate (4).

the addition of $\mathrm{H}_{2} \mathrm{O}(150 \mathrm{~mL})$. The two layers were separated and the aqueous layer was washed with $\mathrm{Et}_{2} \mathrm{O}$ $(3 \times 200 \mathrm{~mL})$. The organic layers were combined, washed with a saturated aqueous $\mathrm{NaHCO}_{3}$ solution, dried over $\mathrm{MgSO}_{4}$, vacuum filtered and concentrated under reduced pressure. To a separate $1 \mathrm{~L}$ round bottom flask was added methyl gallate ( $2.41 \mathrm{~g}, 13.1 \mathrm{mmol}, 1.00 \mathrm{eq}), \mathrm{K}_{2} \mathrm{CO}_{3}(14.3 \mathrm{~g}$, $104 \mathrm{mmol}, 8.00 \mathrm{eq})$ and anhydrous DMF $(300 \mathrm{~mL})$. The crude mesylate $(49.7 \mathrm{mmol}, 1.00 \mathrm{eq})$ was dissolved in DMF $(50 \mathrm{~mL})$ and added to the reaction flask by cannula transfer. The reaction flask was equipped with a reflux condenser and heated to $80^{\circ} \mathrm{C}$ for $12 \mathrm{~h}$ then cooled to room temperature and stirred for an additional $12 \mathrm{~h}$. The reaction was stopped by the addition of $\mathrm{H}_{2} \mathrm{O}(300 \mathrm{~mL})$ and EtOAc $(300 \mathrm{~mL})$. The mixture was transferred to a separation funnel and the aqueous layer was washed with $\mathrm{Et}_{2} \mathrm{O}(3 \times 400 \mathrm{~mL})$. The organic layers were combined, washed copious amounts of $\mathrm{H}_{2} \mathrm{O}$, brine, dried over $\mathrm{MgSO}_{4}$, vacuum filtered and concentrated under reduced pressure. The crude material was purified by flash chromatography (95:5 pentane: $\mathrm{Et}_{2} \mathrm{O}$ then 80:20 pentane: $\mathrm{Et}_{2} \mathrm{O}$ ) on silica gel to provide the desired product as a light yellow oil (14.37 g, 68\% yield over 4 steps) $R_{f}=0.57(80: 20$ hexanes/Et $2 \mathrm{O}) .{ }^{1} \mathrm{H}$ NMR $\left(500 \mathrm{MHz} ; \mathrm{CDCl}_{3}\right)$ $\delta 7.36(\mathrm{~s}, 2 \mathrm{H}), 6.67(\mathrm{~s}, 2 \mathrm{H}), 6.65(\mathrm{~s}, 4 \mathrm{H}), 5.14(\mathrm{~s}, 2 \mathrm{H}), 5.07$ $(\mathrm{s}, 4 \mathrm{H}), 3.86(\mathrm{~s}, 3 \mathrm{H}), 3.84-3.76(\mathrm{~m}, 14 \mathrm{H}), 3.72-3.66$ (m, 4H), 1.75-1.25 (m, 81H), 0.96-0.85 (m, 54H); ${ }^{13} \mathrm{C} \mathrm{NMR}$ $\left(126 \mathrm{MHz}, \mathrm{CDCl}_{3}\right) \delta 166.4,153.5,152.4,142.5,137.6$, $137.5,132.3,131.7,125,109.7,105.6,104.8,75.8,75.7$, 75.3, 71.6, 71.1, 70.9, 52.1, 40.6, 39.4, 30.4, 29.3, 29, 23.8, 23.7, 23.1, 23, 14.2, 14.1, 11.2, 11.1; IR (neat): 2958, 2928, 2873, 2859, 1721, 1591; HRMS-(FAB+)-m/z 1607.262 $\left[(\mathrm{M}+\mathrm{H})^{+}\right.$requires 1607.259].

To a round-bottom flask containing $4(9.90 \mathrm{~g}, 6.15 \mathrm{mmol}$, $1.00 \mathrm{eq})$ was added EtOH $(30 \mathrm{~mL})$ and $\mathrm{KOH}(3.45 \mathrm{~g}$, 


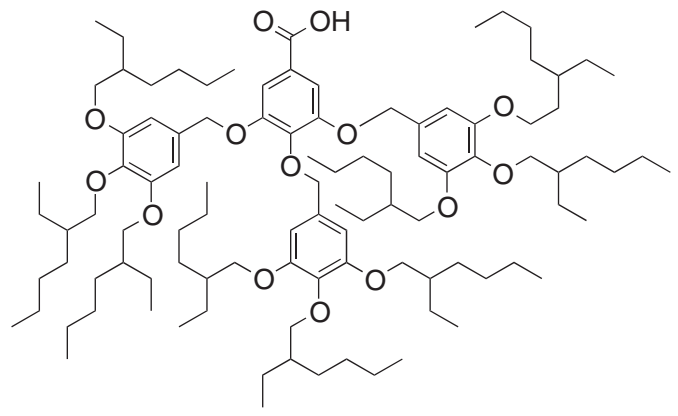

Figure 7

3-((3-((3-ethylheptyl)oxy)-4,5-bis((2-ethylhexyl)oxy)benzyl) oxy)-4,5-bis((3,4,5-tris((2-ethylhexyl)oxy)benzyl)oxy)benzoic acid (5).

$61.5 \mathrm{mmol}, 10.0 \mathrm{eq})$. The flask was equipped with a watercooled reflux condenser and heated to $80^{\circ} \mathrm{C}$ for $5 \mathrm{~h}$. The reaction was allowed to cool to room temperature and stirred for an additional $12 \mathrm{~h}$ then cooled to $0^{\circ} \mathrm{C}$. Once cool, conc. $\mathrm{HCl}$ was added until a neutral $\mathrm{pH}$ was achieved. The mixture was concentrated under reduced pressure then diluted with EtOAc and brine. The solution was transferred to a separation funnel and the two layers were separated. The aqueous layer was washed with EtOAc $(3 \times 150 \mathrm{~mL})$. The organic layers were combined, washed with brine, dried over $\mathrm{MgSO}_{4}$, vacuum filtered and concentrated under reduced pressure. The crude material was purified by flash chromatography (90:10 pentane:EtOAc) on silica gel to provide the desired product as a light yellow oil $(8.78 \mathrm{~g}, 90 \%$ yield $)$ $R_{f}=0.15$ (80:20 pentane/EtOAc). ${ }^{1} \mathrm{H}$ NMR $(500 \mathrm{MHz}$; $\left.\mathrm{CDCl}_{3}\right) \delta 7.43(\mathrm{~s}, 2 \mathrm{H}), 6.66(\mathrm{~s}, 2 \mathrm{H}), 6.65(\mathrm{~s}, 4 \mathrm{H}), 5.15$ $(\mathrm{s}, 2 \mathrm{H}), 5.07(\mathrm{~s}, 4 \mathrm{H}), 3.85-3.74(\mathrm{~m}, 14 \mathrm{H}), 3.69-3.65$ $(\mathrm{m}, 4 \mathrm{H}), 1.73-1.26(\mathrm{~m}, 81 \mathrm{H}), 0.94-0.84(\mathrm{~m}, 54 \mathrm{H}) ;{ }^{13} \mathrm{C}$ NMR $\left(126 \mathrm{MHz}, \mathrm{CDCl}_{3}\right) \delta 170.8,153.7,152.7,143.5$, $137.7,132.4,131.6,124.1,110.4,105.7,105.1,75.98$, $75.94,75.5,71.9,71.3,71.1,40.8,39.7,30.7,30.6,29.5$, 29.3, 29.2, 23.9, 23.8, 23.3, 23.2, 14.3, 14.2, 11.4, 11.3; IR (neat): 2958, 2928, 2873, 1686, 1591; HRMS-[(FAB+) $\mathrm{m} / \mathrm{z} 1594.247$ requires 1594.251$)]$.

To a round-bottom flask containing $5(8.78 \mathrm{~g}, 5.50 \mathrm{mmol}$, $1.00 \mathrm{eq})$ was added anhydrous DCM $(150 \mathrm{~mL})$ and cooled to $0^{\circ} \mathrm{C}$. Once cool, $\mathrm{N}$-(hydroxyethyl)-cis-5-norbornene-exo-2,3 dicarboximide (1.60 g, $6.06 \mathrm{mmol}, 1.10 \mathrm{eq})$, DMAP (335 mg, $2.75 \mathrm{mmol}, 0.500 \mathrm{eq})$ and $\mathrm{N}, \mathrm{N}$-dicyclohexylcarbodiimide $(1.25 \mathrm{~g}, 6.06 \mathrm{mmol}, 1.10 \mathrm{eq})$ were added. The reaction was allowed to stir and gradually warm to room temperature for $12 \mathrm{~h}$. The reaction was stopped by concentration under reduced pressure. The crude material was purified by flash chromatography (85:15 hexanes:EtOAc) on silica gel to provide the desired product as a light yellow oil

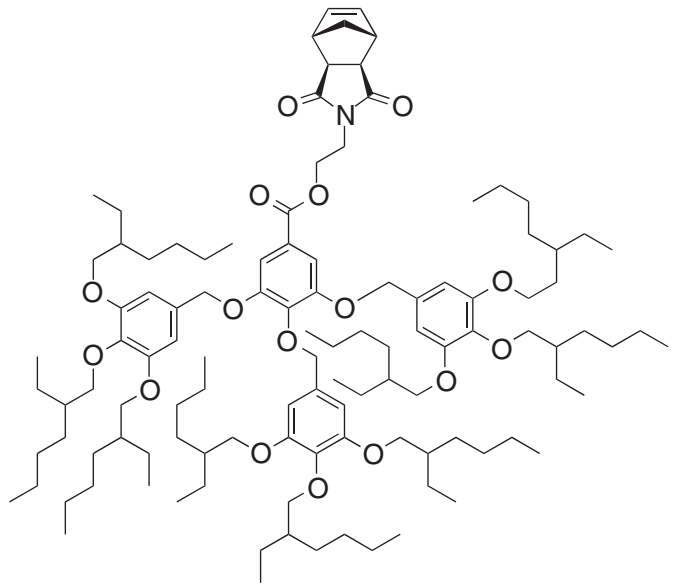

Figure 8

2-((3aR,4R,7S,7aS)-1,3-dioxo-1,3,3a,4,7,7a-hexahydro-2H4,7-methanoisoindol-2-yl)ethyl 3-((3-((3-ethylheptyl)oxy)-4,5bis((2-ethylhexyl)oxy)benzyl)oxy)-4,5-bis((3,4,5-tris((2-ethylhexyl)oxy)benzyl)oxy)benzoate (2G-EHW).

(7.80 g, 77\% yield) $R_{f}=0.37\left(80: 20\right.$ hexanes/EtOAc). ${ }^{1} \mathrm{H}$ NMR $\left(500 \mathrm{MHz} ; \mathrm{CDCl}_{3}\right) \delta 7.33(\mathrm{~s}, 2 \mathrm{H}), 6.67(\mathrm{~s}, 6 \mathrm{H})$, $6.24(\mathrm{t}, J=2 \mathrm{~Hz}, 2 \mathrm{H}), 5.11(\mathrm{~s}, 2 \mathrm{H}), 5.09(\mathrm{~s}, 4 \mathrm{H}), 4.37(\mathrm{t}$, $J=4.5 \mathrm{~Hz}, 2 \mathrm{H}), 3.89(\mathrm{t}, J=5 \mathrm{~Hz}, 2 \mathrm{H}), 3.82-3.74(\mathrm{~m}$, $14 \mathrm{H}), 3.67(\mathrm{dd}, J=2.5,5.0 \mathrm{~Hz}, 4 \mathrm{H}), 3.20(\mathrm{t}, J=1.5 \mathrm{~Hz}$, $2 \mathrm{H}), 2.67$ (d, $J=1 \mathrm{~Hz} .2 \mathrm{H}), 1.71-1.20(\mathrm{~m}, 81 \mathrm{H}), 0.94-0.83$ $(\mathrm{m}, 56 \mathrm{H}) ;{ }^{13} \mathrm{C}$ NMR $\left(126 \mathrm{MHz}, \mathrm{CDCl}_{3}\right) \delta 177.9,165.7$, $153.4,152.6,142.8,137.8,137.6,132.5,131.8,124.6$, $109.6,105.5,105,76,75.9,75.5,71.5,71.2,71.1,61.9$, $47.9,45.4,42.7,40.7,39.7,37.5,30.7,30.6,29.5,29.2$, 23.9, 23.8, 23.3, 23.2, 14.3, 14.2, 11.3, 11.2; HRMS: the detected mass corresponds to a radical cation with $\mathrm{m} / \mathrm{z}$ 1804.3023 corresponding to $[\mathrm{M}+\mathrm{Na}-\mathrm{H}]^{+}$requires 1804.3043 .

\subsection{Synthesis of Second Generation Dendronized Homopolymer}

To a 4 dram vial was added 2G-EHW (160 mg, $0.0900 \mathrm{mmol}, 200 \mathrm{eq})$. To the vial was added a magnetic stir bar and taken into a nitrogen filled glovebox. To the vial was added THF $(1 \mathrm{~mL})$. With rapid stirring, $49 \mu \mathrm{L}$ of an appropriate concentration of $\mathbf{G 3}$ in THF was quickly added via syringe. For kinetic analysis, a $0.05 \mathrm{~mL}$ aliquot of the reaction solution was taken at predetermined time intervals and injected into a $1 \mathrm{~mL}$ septum sealed vial containing a solution of $25 \mu \mathrm{L}$ of ethyl vinyl ether in $0.7 \mathrm{~mL}$ of THF. The aliquot was analyzed by GPC to determine the MW of the polymer. After the solvent was allowed to evaporate from the vials, the polymer residue was dissolved in $\mathrm{CDCl}_{3}$ and analyzed by ${ }^{1} \mathrm{H}$ NMR spectroscopy to determine the 
percent of monomer conversion by comparing the peaks corresponding to the wedge polymer and the unreacted monomer. The polymerization was stopped by the addition of ethyl vinyl ether $(0.2 \mathrm{~mL})$ and addition of methanol $(25 \mathrm{~mL})$. The mixture was allowed to stir for $1 \mathrm{~h}$. The polymer was isolated by vacuum filtration and dried under vacuum at ambient temperature to a constant weight.

2G-EHW Homopolymer: ${ }^{1} \mathrm{H}$ NMR $\left(500 \mathrm{MHz}, \mathrm{CDCl}_{3}\right.$, $\left.25^{\circ} \mathrm{C}\right): \delta \quad 7.37-7.33(\mathrm{~m}), 6.67-6.61(\mathrm{~m}), 5.11-5.04(\mathrm{~m})$, 3.79-3.73 (m), 3.61 (bs), $1.70-1.56(\mathrm{~m}), 1.49-1.24(\mathrm{~m})$, $0.94-0.80(\mathrm{~m}) . d n / d c$ value $=0.1082$.

\section{CONCLUSION}

The synthesis of wedge-type dendronized polymers was achieved via the ruthenium-mediated ROMP of secondgeneration functionalized exo-norborene poly(ether) monomers. These substantially hindered monomers were efficiently polymerized using the highly active $\mathbf{G 3}$ ruthenium carbene initiator. Well-defined $(~(=1.01-1.17)$ high molecular weight $(2100 \mathrm{kDa})$ polymers are accessible. Furthermore, we have demonstrated that a relatively short two carbon linker length is well tolerated in the ring-opening event. This investigation has provided the foundation necessary to explore the synthesis of rigid block copolymer systems with potential for infrared reflecting photonic properties and will be disseminated in due course.

\section{ACKNOWLEDGMENTS}

This work was supported by the NIH (R01 GM031332). P.E.G is grateful to the NIH for a postdoctoral fellowship. We gratefully acknowledge support from the Camille and Henry Dreyfus Postdoctoral Program in Environmental Chemistry. The authors thank Ms. Alice B. Chang for helpful discussions.

\section{REFERENCES}

1 Grubbs R.H. (ed.) (2015) Handbook of Metathesis, $2^{\text {nd }}$ edition, Wiley-VCH, Weinheim, Germany.

2 Hérisson P.J.-L., Chauvin Y. (1970) Makromol. Chem. 141, 161-176.

3 Ivin K.J., Mol J.C. (1997) Olefin Metathesis and Metathesis Polymerization, Academic Press, Inc., San Diego, CA, USA.

4 Dragutan V., Streck R. (2000) Catalytic Polymerization of Cycloolefins. Ionic, Ziegler-Natta and Ring-Opening Metathesis Polymerization, Elsevier Science B.V., Amsterdam, The Netherlands.

5 Frenzel U., Müller B.K.M., Nuyken O. (2005) Handbook of Polymer Synthesis, $2^{\text {nd }}$ ed., Kricheldorf H.R., Nuyken O., Swift G. (eds), Marcel Dekker, New York, NY, USA.
6 Buchmeiser M.R. (2000) Chem. Rev. 100, 1565-1604.

7 Buchmeiser M.R. (2012) Ring-opening metathesis polymerization, in Synthesis of Polymers: New Structures and Methods, $1^{\text {st }}$ ed., Schlüter A.D., Hawker C.J., Sakamoto J. (eds), Wiley-VCH, Weinheim, Germany.

8 Astruc D. (2005) New J. Chem. 29, 42-56.

9 For a review of the ROMP of norbornene and its derivatives see: Floros G., Saragas N., Paraskevopoulou P., Psaroudakis N., Koinis S., Pitsikalis M., Hadjichristidis N., Merti. K., (2012) Polymers 4, 1657-1673.

10 Chang A.B., Miyake G.M., Grubbs R.H. (2014) SequenceControlled Polymer: Synthesis, Self-Assembly and Properties, $1^{\text {st }}$ ed., Lutz J.-F., Meyer T.Y., Ouchi M., Sawamoto M. (eds), American Chemical Society, pp. 161-188.

11 Miyake G.M., Weitekamp R.A., Grubbs R.H. (2015) Handbook of Metathesis Vol. 3: Polymer Synthesis, $2^{\text {nd }}$ edition, Wiley-VCH, Weinheim, Germany, pp. 93-113.

12 Sveinbjörnsson B.R., Weitekamp R.A., Miyake G.M., Xia Y., Atwater H.A., Grubbs R.H. (2012) Proc. Natl. Acad. Sci. U.S.A. 109, 14332-14336.

13 Miyake G.M., Weitekamp R.A., Piunova V.A., Grubbs R.H. (2012) J. Am. Chem. Soc. 134, 14249-14254.

14 Miyake G.M., Piunova V.A., Weitekamp R.A., Grubbs R.H. (2012) Angew. Chem. Int. Ed. 51, 11246-11248.

15 Ge J., Yin Y. (2011) Angew. Chem. Int. Ed. 50, 1492-1522.

16 Galisteo-Loṕez J.F., Ibisate M., Sapienza R., Froufe-Peŕez L.S., Blanco Á., Loṕez C. (2011) Adv. Mater. 23, 30-69.

17 Wang J., Zhang Y., Wang S., Song Y., Jiang L. (2011) Acc. Chem. Res. 44, 405-415.

18 Aguirre C.I., Reguera E., Stein A. (2010) Adv. Funct. Mater. 20, 2565-2578.

19 Moon J.H., Yang S. (2010) Chem. Rev. 110, 547-574.

20 Edrington A.C., Urbas A.M., DeRege P., Chen C.X., Swager T. M., Hadjichristidis N., Xenidou M., Fetters L.J., Joannopoulos J.D., Fink Y., Thomas E.L. (2001) Adv. Mater. 3, 421-425.

21 Piunova V.A., Miyake G.M., Daeffler C.S., Weitekamp R.A., Grubbs R.H. (2013) J. Am. Chem. Soc. 135, 15609-15616.

22 Jung H., Carberry T.P., Weck M. (2011) Macromolecules 44, 9075-9083.

23 Monomer purity significantly affects the efficiency of ROMP see: Xia Y. (2015) Macromolecules 48, 5656-5662.

24 Love J.A., Morgan J.P., Trnka T.M., Grubbs R.H. (2002) Angew. Chem. Int. Ed. 41, 4035-4037.

25 Pangborn A.B., Giardello M.A., Grubbs R.H., Rosen R.K., Trimmer F.J. (1996) Organometallics 15, 1518-1520.

26 Matson J.B., Grubbs R.H. (2008) J. Am. Chem. Soc. 130, 6731-6733.

Manuscript submitted in September 2015

Manuscript accepted in October 2015

Published online in March 2016

Cite this article as: P.E. Guzmán, V.A. Piunova, G.M. Miyake and R.H. Grubbs (2016). Synthesis and Ring-Opening Metathesis Polymerization of Second-Generation Dendronized Poly(ether) Monomers Initiated by Ruthenium Carbenes, Oil Gas Sci. Technol 71, 18. 